\title{
Impact of Delayed Initiation of Non-Invasive Ventilation for Respiratory Distress in Outborn Late- Preterm and Term Neonates
}

\section{Eui Kyung Choi ( $\nabla$ ekchoi03@korea.ac.kr)}

Korea University College of Medicine and School of Medicine https://orcid.org/0000-0003-2192-2648

Kyu Hee Park

Korea University College of Medicine and School of Medicine

Byung Min Choi

Korea University College of Medicine and School of Medicine

\section{Research Article}

Keywords: Respiratory distress syndrome, Outborn, Newborn, Continuous Positive Airway Pressure

Posted Date: August 31st, 2021

DOl: https://doi.org/10.21203/rs.3.rs-787747/v1

License: (c) This work is licensed under a Creative Commons Attribution 4.0 International License.

Read Full License 


\section{Abstract}

The frequency of non-invasive ventilation (NIV) use increased in neonates of all gestational ages with respiratory distress (RD). However, the impact of delayed initiation of NIV support in outborn neonates remains poor understood. The aim of the present study was to identify the impact of delayed initiation of NIV in outborn late-preterm and term neonates.

The medical records of 277 infants (gestational age of $\geq 35$ weeks) who were received NIV as primary respiratory therapy $<24 \mathrm{~h}$ of age between 2016 and 2020 were retrospectively reviewed. Among the 190 outborn neonates, the factors associated with respiratory adverse outcomes were investigated. Infants with $\mathrm{RD}$ divided into two groups, mild $\left(\mathrm{FiO}_{2} \leq 0.3\right)$ and moderate-to-severe $\mathrm{RD}$ group $\left(\mathrm{FiO}_{2}>0.3\right)$, depending on initial oxygen requirement under NIV support.

Median time to start of NIV support at tertiary center was $3.5(2.2-5.0)$ h. Male sex (odds ratio [OR], 2.9; $95 \% \mathrm{Cl}, 1.1-7.7)$, high oxygen requirement $\left(\mathrm{FiO}_{2}>0.3\right)(O R, 4.8 ; 95 \% \mathrm{Cl}, 1.5-15.3)$, and respiratory distress syndrome $(O R, 10.4 ; 95 \% C l, 3.9-27.8)$ were the significant factors associated with adverse outcomes. Subgroup analysis revealed that in the moderate-to-severe RD group, delayed initiation of NIV ( $\geq 3 \mathrm{~h})$ was significantly associated with pulmonary air leakage $(p=0.033)$.

Conclusions: Our study shows that outborn neonates with moderate-to-severe RD who were treated with delayed NIV were associated with an increased likelihood of pulmonary air leakage. Additional prospective studies are needed to establish the optimal timing and methods of NIV support for outborn late-preterm and term infants.

\section{What Is Known}

- Non-invasive ventilation for respiratory support is widely utilized in neonates of all gestational ages.

- Little is known about the impact of delayed initiation of non-invasive ventilation in outborn latepreterm and term neonates.

\section{What is new}

- Male sex, high oxygen requirement $\left(\mathrm{FiO}_{2}>0.3\right)$, and respiratory distress syndrome were the significant factors associated with adverse outcomes.

- Outborn late-preterm and term neonates with high oxygen requirement who were treated with delayed non-invasive ventilation were associated with an increased likelihood of pulmonary air leakage.

\section{Introduction}

Respiratory distress (RD) is one of the most frequent causes of admission to the neonatal intensive care unit (NICU) in term and preterm infants [1, 2]. Among infants admitted to the NICU, $15 \%$ of term infants and $29 \%$ of late-preterm infants develop significant respiratory morbidity. The most common respiratory 
morbidities are transient tachypnea of the newborn (TTN) and respiratory distress syndrome (RDS) [3]. Respiratory signs and/or requirement of oxygen typically present within the first hours of life, often immediately after delivery $[3,4]$.

Current neonatal resuscitation program (NRP) guidelines in the delivery room (DR) recommend continuous positive airway pressure (CPAP) as a corrective measure for all spontaneously breathing infants who present with labored breathing or persistent cyanosis $[5,6]$. Hence, the frequency of CPAP use increased in late-preterm and term infants with RD within the first hours of life [7]. Various modes of non-invasive ventilation (NIV) (e.g., humidified high flow nasal cannula [HHFNC], nasal intermittent positive pressure ventilation [NIPPV], biphasic positive airway pressure [BiPAP]) are used as primary respiratory support together with CPAP, depending on the severity of manifestation $[8,9]$

Despite this practical change, most infants who would have benefitted from NIV are born in community hospitals that do not offer this therapy. Alternatively, these infants receive supplemental oxygen via oxygen hood or nasal cannula while waiting for clinical improvement $[10,11]$. Consequently, they receive high concentrations of inspired oxygen without sufficient distending pressure for a significant length of time. There is some evidence that early application of continuous distending pressure has a clinical benefit over delayed application in very preterm infants [12-14]. Unfortunately, data on the impact of delayed NIV in outborn late-preterm and term infants is scarce. Furthermore, its early use in these infants with mild RD is controversial due to concern for air leakage (e.g., pneumothorax) [15-17].

We conducted this study to assess the factors associated with adverse respiratory outcomes in outborn neonates born at $\geq 35+0$ weeks of gestation, who received NIV as primary respiratory therapy. We hypothesized that delayed initiation of NIV leads to adverse outcomes that vary according to the severity of the underlying disease.

\section{Methods}

We retrospectively reviewed the medical records of 1,709 neonates at $\geq 35^{+0}$ weeks of gestation who were hospitalized in the tertiary referral NICU of Korea University Ansan Hospital between January 2016 and December 2020. Our center is a regional hospital with level III NICU staff and nursing staff experienced in NIV use. During the 5-year period, there were 526 inborn neonates and 1,183 outborn neonates admitted to the NICU. This study was approved by the Institutional Research Ethics Committee of the Korea University Ansan Hospital (2021 AS0193). Patient consent was waived due to retrospective study design.

\section{Inclusion and exclusion criteria}

The enrollment criteria were as follows: (1) neonates with RD but breathing spontaneously and received respiratory support, and (2) gestational age $\geq 35^{+0}$ weeks. We excluded patients with major congenital/chromosomal anomalies, suspected birth asphyxia, meconium-stained amniotic fluid, spontaneous pneumothorax, suspected pneumonia or sepsis, idiopathic persistent pulmonary 
hypertension (PPHN), non-pulmonary issues, those intubated in the DR and immediately placed on mechanical ventilation, and those who received primary respiratory therapy at $\geq 24 \mathrm{~h}$ of age.

\section{Perinatal factors and definitions}

Perinatal data were collected from the discharge summary report and confirmed by a detailed chart review. The collected information included maternal complications, gestational age, birth weight, size for gestational age, sex, mode of delivery, Apgar scores, the need for resuscitation or surfactant replacement therapy, presence of air leakage requiring thoracentesis, ventilatory support (presence, duration, modes, and type; invasive or noninvasive), duration of oxygen therapy, and days of NICU stay.

Data on symptom onset time, method of oxygen administration, and time to initiation of NIV therapy, which was defined as the time (in hours) between symptom onset and the initiation of NIV at the referred hospital, were collected from the neonatal transport summary.

TTN was diagnosed in the presence of RD with onset within $6 \mathrm{~h}$ after birth, defined as respiratory rate $>60$ breaths/min, grunting, nasal flaring, and intercostal, subcostal, and/or suprasternal retractions. Radiographic features of TTN included bilateral alveolar and interstitial edema, prominent pulmonary vascular pattern with increased perihilar markings, hyperinflated lungs, and/or fluid in the interlobar fissure. RDS was diagnosed based on the presence of at least two of the following symptoms: the need for supplemental oxygen, tachypnea, intercostal retraction, and grunting, with exclusion of other causes of RD. Radiographic features of RDS included low lung volumes and air bronchograms with diffuse, bilateral, and ground glass fields prior to surfactant treatment.

Neonates with RD were divided into two groups depending on their initial oxygen requirement with any NIV modalities; neonates in the mild RD group received a fraction of inspired oxygen $\left(\mathrm{FiO}_{2}\right) \leq 30$, while infants in the moderate-to-severe $\mathrm{RD}$ group received a $\mathrm{FiO}_{2}>30$.

\section{Respiratory support techniques}

Once admitted to the NICU, the neonates were provided primary treatment in the form of four possible NIV devices: nasal CPAP, synchronized nasal intermittent positive pressure ventilation (sNIPPV), BiPAP, and HHFNC. The choice of whether and when to use NIV was at the discretion of the medical team, with no specific unit guideline on the choice of one strategy over another.

CPAP, BiPAP, and sNIPPV modes were delivered using Infant Flow SiPAP (Carefusion, USA) and Medin CNO (Medin Medical Innovations $\mathrm{GmbH}$ ). To ensure that blood gas analysis results were within the normal range, infants on nasal CPAP received a positive end-expiratory pressure (PEEP) of $5 \mathrm{~cm} \mathrm{H}_{2} \mathrm{O}$, which was adjusted to 4-7 $\mathrm{cm} \mathrm{H}_{2} \mathrm{O}$, depending on the infant's respiratory condition. Infants on BiPAP received a baseline PEEP of $5 \mathrm{~cm} \mathrm{H}_{2} \mathrm{O}$, a high PEEP of $8 \mathrm{~cm} \mathrm{H} \mathrm{H}_{2} \mathrm{O}$, and a respiratory rate of $30 /$ min with an initial inspiratory time $(\mathrm{Ti})$ of $0.5 \mathrm{~s}$. The baseline PEEP was adjusted to $4-7 \mathrm{~cm} \mathrm{H}_{2} \mathrm{O}$, and high PEEP was adjusted to 7-10 $\mathrm{cm} \mathrm{H}_{2} \mathrm{O}$. Flow-sNIPPV was delivered with the following parameters: Ti, 0.3-0.35 s; peak 
inspiratory pressure (PIP), 8-12 $\mathrm{cm} \mathrm{H}_{2} \mathrm{O}$; PEEP, 4-6 $\mathrm{cm} \mathrm{H}_{2} \mathrm{O}$; back-up rate, $40 \mathrm{bpm}$. $\mathrm{FiO}_{2}$ was adjusted in each device until a $\mathrm{SpO}_{2}$ of $88 \%-94 \%$ was maintained.

HHFNC support was delivered using the Optiflow System (Fisher \& Paykel Optiflow System, Healthcare, Auckland, New Zealand), with short binasal prongs. Infants received gas flow of $5 \mathrm{~L} / \mathrm{min}$ initially, which was adjusted to $3-7 \mathrm{~L} / \mathrm{min}$, according to their condition.

\section{Outcomes}

Adverse outcomes were defined as mechanical ventilation therapy or the incidence of pulmonary air leakage. The latter was defined as pneumothorax or pneumomediastinum with RD that occurred during hospitalization, as diagnosed with chest radiography.

\section{Statistical analysis}

All data analyses were performed using SPSS 20.0 for Windows (SPSS Inc., Chicago, IL, USA). Continuous variables were analysed using the t-test and Mann-Whitney $U$ test for normal and skewed distributions, respectively. Proportions were tested using chi-squared and Fisher's exact tests; statistical significance was set at $p<0.05$. The significant variables identified in the univariate analysis were further assessed using a multivariable logistic regression analysis. Data are presented as mean \pm standard deviation $(S D)$, median and range, or rate.

\section{Results}

Out of the 1,709 neonates at $\geq 35^{+0}$ weeks of gestation who underwent hospitalization between January 2016 and December 2020, 502 late-preterm and term neonates with RD required respiratory support. Once the differential diagnoses were excluded, 277 neonates remained; this was further divided into inborn ( $n=$ $87)$ and outborn $(n=190)$ patients, with the latter serving as the subjects of this study (Figure 1$)$.

The demographic and clinical data of the patients are presented in Table 1. The mean gestational age and birth weight of the patients were $37.9 \pm 1.5$ weeks and 3,228 \pm 486 grams, respectively. Seventy-two percent $(n=135)$ of the neonates showed symptoms of RD shortly after birth and $65.3 \%(n=124)$ required oxygen supplementation at DR. None of the outborn neonates received CPAP in the DR. The median time to start of NIV at our hospital was $3.5(2.2-5.0) \mathrm{h}$, and the initial median $\mathrm{SpO}_{2}$ and $\mathrm{FiO}_{2}$ were $90 \%$ and 0.3 , respectively. More cases of $\operatorname{TTN}(n=116 ; 61.1 \%)$ were diagnosed than of RDS $(n=74$; $38.9 \%)$. Outborn neonates had a greater history of mechanical ventilation $(24.7 \%$ vs. $4.6 \%, p<0.001)$ and air leakage $(17.4 \%$ vs. $1.1 \%, p<0.001)$ than inborn patients (Supplemental Table 1).

The following factors were significantly associated with adverse outcomes during hospitalization (Table 2): A younger gestational age (GA; $37.3 \pm 1.0$ vs. $38.1 \pm 1.1$ weeks, $p=0.003$ ), lower birth weight (3 $184 \pm$ 384 vs. $3251 \pm 534$ grams, $p=0.014)$, male sex ( $72.7 \%$ vs. $49.2 \%, p=0.002)$, cesarean section ( $84.8 \%$ vs. $62.1 \%, p=0.001)$, lower initial $\mathrm{SpO}_{2}(83 \%$ [74.5-91.5] vs. $92 \%$ [87-97], $p<0.001)$, higher initial $\mathrm{FiO}_{2}(31.5$ 
[26.5-36.5] vs. 25 [21-29], $p<0.001)$, lower initial pH (7.20 [7.15-7.23] vs. 7.25 [7.21-7.32], $p<0.001)$, higher $\mathrm{CO}_{2}(61$ [54-70] vs. 51 [44-60], $p<0.001)$ and a primary diagnosis of $\mathrm{RDS}(83.3 \%$ vs. $15.3 \%, p$ $<0.001)$. There was no significant difference in the time of NIV initiation in the NICU. Logistic regression analysis on the significant variables further revealed that the significant risk factors for adverse outcomes were male sex (odds ratio $[O R], 2.9 ; 95 \%$ confidence interval $[C l, 1.1-7.7)$, initial $\mathrm{FiO}_{2}>30(O R$, 4.8; $95 \% C l, 1.5-15.3)$, and a primary diagnosis of RDS (OR, 10.4; 95\% Cl, 3.9-27.8) (Table 3).

Table 4 shows the clinical data for the mild and moderate-to-severe RD groups, further divided according to the time of NIV initiation (with $3 \mathrm{~h}$ as the cut-off). This allowed us to clarify the effects of underlying disease severity. In infants with moderate-to-severe RD, a significantly high incidence of air leakage occurred when the initiation of NIV therapy was delayed by $>3 \mathrm{~h}$, as compared to when NIV therapy was initiated earlier ( $35.7 \%$ vs. $5.9 \%, p=0.033$ ) (Figure 2). The median time to identify the pulmonary air leakage from initiation of first NIV was not significantly different between two groups (15.5 h [11.0-32.7] vs. $21.5 \mathrm{~h}$ [15.6-26.4]. $p=0.703$ ) (Table 5). There was no significant difference in treatment of pulmonary air leakage $(p=1.000), 63.6 \%$ of neonates with mild RD and $54.5 \%$ of neonates with moderate-to-severe RD were treated with conservative managements such as observation or oxygen therapy (Supplemental Table 2).

\section{Discussion}

To our knowledge, this is the first study to directly investigate the association between delayed initiation of NIV and pulmonary air leakage in outborn late-preterm and term neonates with significant oxygen requirement.

Non-invasive respiratory support (e.g., CPAP utilization) seems to be increasing, particularly in later gestational age categories, following the release of the NRP guidelines in 2011. Moreover, recent studies have shown that NIV, as compared to free flow $\mathrm{O}_{2}$, may decrease the duration and severity of RD in latepreterm and term infants with TTN or RDS $[9,10,18,19]$. In the present study, we found that out of the total number of neonates who were in RD and breathing spontaneously, 83\% received CPAP or noninvasive positive pressure ventilation (NPPV) as their primary respiratory support, whereas $17 \%$ received HHFNC after NICU arrival.

In agreement with previous studies, a low GA, male sex, birth by cesarean section, high oxygen requirement, and RDS were significant factors associated with adverse outcomes in our cohort $[3,20]$. Additionally, our results showed that the frequency of air leakage was particularly high when there was a delay in respiratory support in cases of moderate-to-severe RD; while oxygen supplementation was initiated in all referred hospitals prior to NICU arrival, continuous pressure support was delayed due to the lack of appropriate devices. In a few small studies in the pre-surfactant era, delayed initiation of CPAP in infants with RDS was associated with significant development of pneumothorax [12, 21, 22]. The resulting difference in outcomes can be attributed to the alteration of the course of RDS among infants treated with continuous distending pressure early [21, 22]. Smithhart et al. showed in a large birth cohort 
study that the incidence of pneumothorax decreased with oxygen requirement among neonates who received early CPAP in the DR, suggesting that the risk of CPAP-induced pneumothorax is lower in lungs with underlying disease [15]. Similarly, a recent study by Hirata et al. reported that adverse prognosis of severe TTN was strongly associated with a longer time between birth and transport to a level III NICU [23]. This is consistent with the results of our study; we classified the severity of RD, allowing us to further clarify the effects of the primary disease.

The impact of outborn status on the greater risk of severe respiratory morbidities is unclear, given the inconsistencies in diagnosis and management [24-27]. In the present study, the incidence of air leakage in outborn neonates $(17.4 \%)$ was higher than that in inborn neonates $(1.1 \%)$. Additionally, RDS was the underlying primary lung disease in a large number of outborn neonates. Previous studies that utilized the national epidemiologic data of Korea reported that among term infants with RDS, the incidence of pneumothorax notably increased from $6.9 \%$ to $11.7 \%$ over 5 years. In contrast, there was no change in the incidence of pneumothorax in preterm infants with RDS [28]. The clinical characteristics of outborn and inborn neonates were also different, suggesting a different underlying mechanism of pneumothorax and/or resuscitation quality in the DR and during medical transport [26-29]. It is possible that the initiation of delayed CPAP in these neonates augment the levels of lung distending pressure towards the threshold for lung rupture; this is due to the fact that neonates born at term or moderate-to-late-preterm are capable of generating auto-positive end-expiratory pressure through grunting and struggling [25]. Careful monitoring and precise adjustment of modes of respiratory support for air leakage are needed in outborn neonates with moderate-to-severe RD, including those diagnosed with RDS. In addition, based on the findings of our study, we believe that early initiation of continuous distending pressure (e.g., CPAP) might lead to a marked reduction in adverse outcomes. Immediate application of non-invasive respiratory support, instead of oxygen supplementation, should be considered in late-preterm and term neonates who show apparent respiratory symptoms and significant oxygen requirement. Additional prospective studies are needed to establish the optimal timing and methods of primary respiratory support.

However, this study has several limitations-one of which is its retrospective design. The restriction of the study to neonates who were admitted to the NICU resulted in a small sample size. In the current study, antenatal steroids were not administered to the mothers of all outborn neonates; this is not in concordance with the by the American College of Obstetricians and Gynecologists (ACOG) guidelines in 2020 which recommend the administration of betamethasone for pregnant women who are at risk of having a late-preterm birth [30]. The indication for each NIV device was at the discretion of the attending neonatologist, which may have influenced the outcomes. Notably, there were no significant differences in the type of primary respiratory support between the inborn and outborn neonates, with or without adverse outcomes. Since the accessibility of outborn neonates with RD varies widely by center, our results may not be generalizable to other centers where the characteristics of patients differ from ours.

In conclusion, this study confirmed that outborn infants with moderate-to-severe RD who were treated with delayed non-invasive respiratory support were associated with an increased likelihood of pulmonary air leakage. 


\section{Declarations}

\section{Funding}

This research received no external funding.

\section{Conflicts of interest}

The authors declare no conflict of interest

\section{Availability of data and material}

The datasets used and/or analyzed during the current study are available from the corresponding author on reasonable request.

\section{Code availability}

Not applicable

\section{Authors' Contributions}

Eui Kyung Choi: Primary author, Data Collection, Data analysis, Manuscript writing.

Kyu Hee Park: Data Collection

Byung Min Choi: Drafting of the manuscript, Editing, Critical revision of the manuscript, Responsible for the overall content.

All authors provided contributions, have read and approved the final version.

\section{Ethics approval}

This study was approved by the Institutional Research Ethics Committee of the Korea University Ansan Hospital (2021AS0193).

\section{Consent to participate}

Patient consent was waived due to retrospective study design.

\section{Consent for publication}

Written informed consent for publication was obtained from all authors.

\section{List Of Abbreviations}

ACOG American College of Obstetricians and Gynecologists 
BiPAP biphasic positive airway pressure

CPAP continuous positive airway pressure

DR delivery room

$\mathrm{FiO}_{2}$ fraction of inspired oxygen

HHFNC humidified high flow nasal cannula

NICU neonatal intensive care unit

NIPPV nasal intermittent positive pressure ventilation

NIV non-invasive ventilation

NPPV non-invasive positive pressure ventilation

NRP neonatal resuscitation program

OR odds ratio

PEEP positive end-expiratory pressure

PIP peak inspiratory pressure

PPHN persistent pulmonary hypertension

$\mathrm{RD}$ respiratory distress

RDS respiratory distress syndrome

SD standard deviation

sNIPPV synchronized nasal intermittent positive pressure ventilation

Ti inspiratory time

TTN transient tachypnea of the newborn

\section{References}

1. Reuter S, Moser C, Baack M (2014) Respiratory distress in the newborn. Pediatr Rev 35:417-428. https://doi.org/10.1542/pir.35-10-417 quiz 429.

2. Qian L, Liu C, Zhuang W et al (2008) Neonatal respiratory failure: a 12-month clinical epidemiologic study from 2004 to 2005 in China. Pediatrics 121:e1115-e1124. https://doi.org/10.1542/peds.2006- 
3. Consortium on Safe L, Hibbard JU, Wilkins I et al (2010) Respiratory morbidity in late preterm births. JAMA 304:419-425. https://doi.org/10.1001/jama.2010.1015

4. Pramanik AK, Rangaswamy N, Gates T (2015) Neonatal respiratory distress: a practical approach to its diagnosis and management. Pediatr Clin North Am 62:453-469.

https://doi.org/10.1016/j.pcl.2014.11.008

5. Wyckoff MH, Aziz K, Escobedo MB, Kapadia VS, Kattwinkel J, Perlman JM, Simon WM, Weiner GM, Zaichkin JG (2015) Part 13: Neonatal Resuscitation: 2015 American Heart Association Guidelines Update for Cardiopulmonary Resuscitation and Emergency Cardiovascular Care. Circulation 132:S543-S560. https://doi.org/10.1161/cir.0000000000000267

6. Aziz K, Lee CHC, Escobedo MB et al (2021) Part 5: Neonatal Resuscitation 2020 American Heart Association Guidelines for Cardiopulmonary Resuscitation and Emergency Cardiovascular Care. Pediatrics 147 https://doi.org/10.1542/peds.2020-038505E

7. Spillane NT, Macalintal F, Nyirenda T, Golombek SG (2021) What happens to 35 week infants that receive delivery room continuous positive airway pressure? J Perinatol. https://doi.org/10.1038/s41372-020-00883-w

8. Moresco L, Romantsik O, Calevo MG, Bruschettini M (2020) Non-invasive respiratory support for the management of transient tachypnea of the newborn. Cochrane Database Syst Rev 4:Cd013231. https://doi.org/10.1002/14651858.CD013231.pub2

9. Cimino C, Saporito MAN, Vitaliti G, Pavone P, Mauceri L, Gitto E, Corsello G, Lubrano R, Falsaperla R (2020) N-BiPAP vs n-CPAP in term neonate with respiratory distress syndrome. Early Hum Dev 142:104965

10. Buckmaster AG, Arnolda G, Wright IM, Foster JP, Henderson-Smart DJ (2007) Continuous positive airway pressure therapy for infants with respiratory distress in non tertiary care centers: a randomized, controlled trial. Pediatrics 120:509-518. https://doi.org/10.1542/peds.2007-0775

11. Frey B, Shann F (2003) Oxygen administration in infants. Arch Dis Child Fetal Neonatal Ed 88:F84F88. https://doi.org/10.1136/fn.88.2.f84

12. Ho JJ, Subramaniam P, Sivakaanthan A, Davis PG (2020) Early versus delayed continuous positive airway pressure (CPAP) for respiratory distress in preterm infants. Cochrane Database Syst Rev 10:Cd002975. https://doi.org/10.1002/14651858.CD002975.pub2

13. Schmölzer GM, Kumar M, Pichler G, Aziz K, O'Reilly M, Cheung PY (2013) Non-invasive versus invasive respiratory support in preterm infants at birth: systematic review and meta-analysis. Bmj 347:f5980. https://doi.org/10.1136/bmj.f5980

14. Miksch RM, Armbrust S, Pahnke J, Fusch C (2008) Outcome of very low birthweight infants after introducing a new standard regime with the early use of nasal CPAP. Eur J Pediatr 167:909-916. https://doi.org/10.1007/s00431-007-0646-1

15. Smithhart W, Wyckoff MH, Kapadia V, Jaleel M, Kakkilaya V, Brown LS, Nelson DB, Brion LP (2019) Delivery Room Continuous Positive Airway Pressure and Pneumothorax. Pediatrics 144 
https://doi.org/10.1542/peds.2019-0756

16. Clevenger L, Britton JR (2017) Delivery room continuous positive airway pressure and early pneumothorax in term newborn infants. J Neonatal Perinatal Med 10:157-161. https://doi.org/10.3233/npm-171694

17. Hishikawa K, Goishi K, Fujiwara T, Kaneshige M, Ito Y, Sago H (2015) Pulmonary air leak associated with CPAP at term birth resuscitation. Arch Dis Child Fetal Neonatal Ed 100:F382-F387. https://doi.org/10.1136/archdischild-2014-307891

18. Osman AM, El-Farrash RA, Mohammed EH (2019) Early rescue Neopuff for infants with transient tachypnea of newborn: a randomized controlled trial. J Matern Fetal Neonatal Med 32:597-603. https://doi.org/10.1080/14767058.2017.1387531

19. Chiruvolu A, Claunch KM, Garcia AJ, Petrey B, Hammonds K, Mallett LH (2021) Effect of continuous positive airway pressure versus nasal cannula on late preterm and term infants with transient tachypnea of the newborn. J Perinatol. https://doi.org/10.1038/s41372-021-01068-9

20. Gulczyńska E, Szczapa T, Hożejowski R, Borszewska-Kornacka MK, Rutkowska M (2019) Fraction of Inspired Oxygen as a Predictor of CPAP Failure in Preterm Infants with Respiratory Distress Syndrome: A Prospective Multicenter Study. Neonatology 116:171-178. https://doi.org/10.1159/000499674

21. Hegyi T, Hiatt IM (1981) The effect of continuous positive airway pressure on the course of respiratory distress syndrome: the benefits on early initiation. Crit Care Med 9:38-41. https://doi.org/10.1097/00003246-198101000-00009

22. Allen LP, Reynolds ER, Rivers RP, Le Souëf PM, Wimberley PD (1977) Controlled trial of continuous positive airway pressure given by face mask for hyaline membrane disease. Arch Dis Child 52:373378. https://doi.org/10.1136/adc.52.5.373

23. Hirata K, Nozaki M, Mochizuki N, Hirano S, Wada K (2019) Impact of Time to Neonatal Transport on Outcomes of Transient Tachypnea of the Newborn. Am J Perinatol 36:1090-1096. https://doi.org/10.1055/s-0038-1676490

24. Boo NY, Cheah IG, Malaysian National Neonatal R (2011) Risk factors associated with pneumothorax in Malaysian neonatal intensive care units. J Paediatr Child Health 47:183-190. https://doi.org/10.1111/j.1440-1754.2010.01944.x

25. Duong HH, Mirea L, Shah PS, Yang J, Lee SK, Sankaran K (2014) Pneumothorax in neonates: Trends, predictors and outcomes. J Neonatal Perinatal Med 7:29-38. https://doi.org/10.3233/npm-1473813

26. Trevisanuto D, Doglioni N, Ferrarese P, Vedovato S, Cosmi E, Zanardo V (2005) Neonatal pneumothorax: comparison between neonatal transfers and inborn infants. J Perinat Med 33:449454. https://doi.org/10.1515/jpm.2005.079

27. Cornette L, Mulder A, Debeer A, Malfilâtre G, Rigo V, Cools F, Danhaive O (2021) Surfactant use in late preterm infants: a survey among Belgian neonatologists. Eur J Pediatr 180:885-892. https://doi.org/10.1007/s00431-020-03806-1 
28. Shin JE, Yoon SJ, Lim J, Han J, Eun HS, Park MS, Park KI, Lee SM (2020) Pulmonary Surfactant Replacement Therapy for Respiratory Distress Syndrome in Neonates: a Nationwide Epidemiological Study in Korea. J Korean Med Sci 35:e253. https://doi.org/10.3346/jkms.2020.35.e253

29. Fang JL, Mara KC, Weaver AL, Clark RH, Carey WA (2020) Outcomes of outborn extremely preterm neonates admitted to a NICU with respiratory distress. Arch Dis Child Fetal Neonatal Ed 105:33-40. https://doi.org/10.1136/archdischild-2018-316244

30. Siegler Y, Weiner Z, Solt I (2020) ACOG Practice Bulletin No. 217: Prelabor Rupture of Membranes. Obstet Gynecol 136:1061. https://doi.org/10.1097/AOG.0000000000004142

\section{Tables}

Table 1. Demographic and clinical data of the outborn neonates with respiratory distress 


\begin{tabular}{|c|c|}
\hline Characteristics & Outborn $(n=190)$ \\
\hline Gestational age, mean (SD), weeks & $37.9 \pm 1.5$ \\
\hline Birth weight, mean (SD), g & $3,228 \pm 486$ \\
\hline Male, no (\%) & $109(57.4 \%)$ \\
\hline Small for gestational age, no (\%) & $3(0.6 \%)$ \\
\hline Large for gestational age, no (\%) & $29(15.3 \%)$ \\
\hline Apgar score, 1 min, median (IQR), & $8(8-9)$ \\
\hline Apgar score, 5 min, median (IQR), & $9(9-10)$ \\
\hline Cesarean section, no (\%) & 133/190 (70.0\%) \\
\hline Maternal hypertensive disorder, no (\%) & $6 / 190(3.2 \%)$ \\
\hline Diabetes mellitus, no (\%) & $19 / 190(10.0 \%)$ \\
\hline Antenatal steroid (complete), no (\%) & $0 / 190(0.0 \%)$ \\
\hline Twin, no (\%) & $8 / 190(4.2 \%)$ \\
\hline \multicolumn{2}{|l|}{ Delivery room management } \\
\hline Flow Oxygen, no (\%) & $124 / 190(65.3 \%)$ \\
\hline CPAP, no (\%) & $0 / 190(0.0)$ \\
\hline PPV, no (\%) & $14 / 190(7.4)$ \\
\hline Symptom onset time, median (IQR), min & $0(0-60)$ \\
\hline Time to respiratory support, median (IQR), hour & $3.5(2.2-5.0)$ \\
\hline Initial $\mathrm{SpO}_{2}$, median (IQR), \% & $91(83-96)$ \\
\hline Initial $\mathrm{FiO}_{2}$, median (IQR), \% & $30(25-30)$ \\
\hline $\mathrm{pH}$ on admission, median (IQR) & $7.23(7.19-7.28)$ \\
\hline capillary $\mathrm{CO}_{2}$ on admission, median (IQR), $\mathrm{mmHg}$ & $55.2(46.0-63.0)$ \\
\hline Body temperature on admission, median (IQR), ${ }^{\circ} \mathrm{C}$ & $36.6(36.5-37.0)$ \\
\hline \multicolumn{2}{|l|}{ Initial Therapy } \\
\hline HHFNC, no (\%) & $32 / 190(16.8 \%)$ \\
\hline CPAP or NPPV, no (\%) & 158/190 (83.2\%) \\
\hline \multicolumn{2}{|l|}{ Primary Diagnosis } \\
\hline TTN, no (\%) & 116/190 (61.1\%) \\
\hline
\end{tabular}

Page 13/19 


\begin{tabular}{|ll|}
\hline RDS, no (\%) & $74 / 190(38.9 \%)$ \\
\hline Air leakage during hospitalization, no (\%) & $33 / 190(17.4 \%)$ \\
\hline MV during hospitalization, no (\%) & $47 / 190(24.7 \%)$ \\
\hline Respiratory support days, median (IQR), days & $3.5(2.8-5.0)$ \\
\hline Mortality, no (\%) & $1 / 190(0.5 \%)$ \\
\hline Hospital stays, median (IQR), days & $8(6-10)$ \\
\hline
\end{tabular}

SD: standard deviation; IQR: interquartile range; CPAP: continuous positive airway pressure; PPV: positive pressure ventilation; $\mathrm{SpO}_{2}$ : saturation of partial pressure oxygen; $\mathrm{FiO}_{2}$ : fraction of inspired oxygen; $\mathrm{CO}_{2}$ : carbon dioxide; HHFNC: humidified high flow nasal cannula; NPPV: non-invasive positive pressure ventilation; TTN: transient tachypnea of the newborn; RDS: respiratory distress syndrome; MV: mechanical ventilation

Table 2. Factors associated with adverse outcomes during hospitalization in outborn neonates 


\begin{tabular}{|c|c|c|c|}
\hline & $\begin{array}{l}\text { No } \\
\text { complication } \\
(n=124)\end{array}$ & $\begin{array}{l}\text { Air leakage or mechanical ventilation } \\
\text { during hospitalization } \\
(n=66)\end{array}$ & $P$ \\
\hline $\begin{array}{l}\text { Gestational age, mean (SD), } \\
\text { weeks }\end{array}$ & $38.1 \pm 1.1$ & $37.3 \pm 1.0$ & 0.003 \\
\hline Birth weight, mean (SD), g & $3,251 \pm 534$ & $3,184 \pm 384$ & 0.014 \\
\hline Male, no (\%) & $\begin{array}{l}61 / 124 \\
(49.2)\end{array}$ & $48 / 66(72.7)$ & 0.002 \\
\hline Cesarean section, no (\%) & $\begin{array}{l}77 / 124 \\
(62.1)\end{array}$ & $56 / 66(84.8)$ & 0.001 \\
\hline Small for gestational age, no (\%) & $3 / 124(2.4)$ & $0 / 66(0)$ & 0.553 \\
\hline Large for gestational age, no (\%) & $\begin{array}{l}16 / 124 \\
(15.3)\end{array}$ & $10 / 66(15.2)$ & 0.975 \\
\hline $\begin{array}{l}\text { Maternal hypertensive disorder, } \\
\text { no (\%) }\end{array}$ & $3 / 124(2.4)$ & $3 / 66(4.5)$ & 0.420 \\
\hline Diabetes mellitus, no (\%) & $12 / 124(9.7)$ & $7 / 66(10.6)$ & 0.839 \\
\hline \multicolumn{4}{|l|}{ Delivery room management } \\
\hline Flow Oxygen, no (\%) & $\begin{array}{l}83 / 124 \\
(66.9)\end{array}$ & $41 / 66(62.1)$ & 0.507 \\
\hline CPAP, no (\%) & $0 / 124(0)$ & $0 / 66(0)$ & \\
\hline PPV, no (\%) & $8 / 124(6.5)$ & $6 / 66(9.1)$ & 0.507 \\
\hline $\begin{array}{l}\text { Symptom onset time, median } \\
\text { (IQR), min }\end{array}$ & $0(0-0)$ & $0(0-60)$ & 0.315 \\
\hline $\begin{array}{l}\text { Time to respiratory support, } \\
\text { median (IQR), hour }\end{array}$ & $3.5(2.3-5.2)$ & $4.0(2.9-5.2)$ & 0.437 \\
\hline Initial $\mathrm{SpO}_{2}$, median (IQR), \% & $92(87-97)$ & $83(74.5-91.5)$ & 0.000 \\
\hline Initial $\mathrm{FiO}_{2}$, median (IQR), \% & $25(21-29)$ & $31.5(26.5-36.5)$ & 0.000 \\
\hline Initial $\mathrm{FiO}_{2}>30 \%$, no (\%) & $12 / 124(9.7)$ & $33 / 66(50.0)$ & 0.000 \\
\hline $\mathrm{pH}$ on admission, median (IQR) & $\begin{array}{l}7.25(7.21- \\
7.32)\end{array}$ & $7.20(7.15-7.23)$ & 0.000 \\
\hline $\begin{array}{l}\text { Capillary } \mathrm{CO}_{2} \text { on admission, } \\
\text { median (IQR), } \mathrm{mmHg}\end{array}$ & $51(44-60)$ & $61(54-70)$ & 0.000 \\
\hline $\begin{array}{l}\text { Body temperature on admission, } \\
\text { median (IQR), }{ }^{\circ} \mathrm{C}\end{array}$ & $\begin{array}{l}36.6(36.5- \\
37.0)\end{array}$ & $36.6(36.5-37.0)$ & 0.635 \\
\hline Initial Therapy & & & 0.299 \\
\hline
\end{tabular}




\begin{tabular}{|c|c|c|c|}
\hline HHFNC, no (\%) & $\begin{array}{l}20 / 124 \\
(16.1)\end{array}$ & $7 / 66(10.6)$ & \\
\hline CPAP/NPPV, no (\%) & $\begin{array}{l}104 / 124 \\
(83.9)\end{array}$ & $59 / 66(89.4)$ & \\
\hline \multicolumn{4}{|l|}{ Primary Diagnosis } \\
\hline TTN, no (\%) & $\begin{array}{l}105 / 124 \\
(84.7)\end{array}$ & $11 / 66(16.7)$ & \\
\hline RDS, no (\%) & $\begin{array}{l}19 / 124 \\
(15.3)\end{array}$ & $55 / 66(83.3)$ & 0.000 \\
\hline $\begin{array}{l}\text { Respiratory support days, } \\
\text { median (IQR), days }\end{array}$ & $3(2-4)$ & $6(4-8)$ & 0.000 \\
\hline $\begin{array}{l}\text { Hospital stays, median (IQR), } \\
\text { days }\end{array}$ & $7(6-8)$ & $10(8-12)$ & 0.000 \\
\hline
\end{tabular}

SD: standard deviation; IQR: interquartile range; CPAP: continuous positive airway pressure; PPV: positive pressure ventilation; $\mathrm{SpO}_{2}$ : saturation of partial pressure oxygen; $\mathrm{FiO}_{2}$ : fraction of inspired oxygen; $\mathrm{CO}_{2}$ : carbon dioxide; HHFNC: humidified high flow nasal cannula; NPPV: non-invasive positive pressure ventilation; TTN: transient tachypnea of the newborn; RDS: respiratory distress syndrome; MV: mechanical ventilation

Table 3. Multiple logistic analysis of adverse outcomes in outborn neonates with respiratory distress

\begin{tabular}{|lllll|}
\hline Clinical characteristics & Unadjusted OR (95\%) & $P$-value & Adjusted OR & $P$ \\
\hline Male & $2.8(1.4-5.3)$ & 0.002 & $2.9(1.1-7.7)$ & 0.032 \\
\hline Initial $\mathrm{FiO}_{2}>30$ & $9.3(4.3-20.1$ & 0.000 & $4.8(1.5-15.3)$ & 0.008 \\
\hline Respiratory distress syndrome & $27.6(12.3-62.2)$ & 0.000 & $10.4(3.872-27.832)$ & 0.000 \\
\hline
\end{tabular}

Table 4. Clinical data grouped according to the time of NIV initiation $(3 \mathrm{~h})$ in mild or moderate-to-severe respiratory distress 
Mild RD $(n=145)$

\begin{tabular}{|c|c|c|c|c|c|c|}
\hline & $\begin{array}{l}\text { NIV initiated } \\
<3 \mathrm{~h}(n=55 \\
)\end{array}$ & $\begin{array}{l}\text { NIV initiated } \\
\geq 3 \mathrm{~h}(n= \\
90)\end{array}$ & $\begin{array}{l}P- \\
\text { value }\end{array}$ & $\begin{array}{l}\text { NIV } \\
\text { initiated } \\
<3 \mathrm{~h} \\
(n=17)\end{array}$ & $\begin{array}{l}\text { NIV } \\
\text { initiated } \geq \\
3 \mathrm{~h}(n=28)\end{array}$ & $P$ \\
\hline $\begin{array}{l}\text { Gestational age, } \\
\text { median (IQR), weeks }\end{array}$ & $\begin{array}{l}37.9(36.6- \\
39.1)\end{array}$ & $\begin{array}{l}37.9(36.7- \\
39.0)\end{array}$ & 0.787 & $\begin{array}{l}37.6 \\
(37.1- \\
38.1)\end{array}$ & $\begin{array}{l}37.6(36.6- \\
38.3)\end{array}$ & 0.725 \\
\hline $\begin{array}{l}\text { Birth weight, median } \\
\text { (IQR), g }\end{array}$ & $\begin{array}{l}3,190 \\
(2,850- \\
3,650)\end{array}$ & $\begin{array}{l}3,280 \\
(2,818- \\
3,593)\end{array}$ & 0.736 & $\begin{array}{l}3,135 \\
(2,850- \\
3,440)\end{array}$ & $\begin{array}{l}3,175 \\
(2,938- \\
3,430)\end{array}$ & 0.606 \\
\hline Male, no (\%) & $34 / 55$ (61.8) & $50 / 90(55.6)$ & 0.459 & $\begin{array}{l}9 / 17 \\
(52.9)\end{array}$ & $\begin{array}{l}16 / 28 \\
(57.1)\end{array}$ & 0.783 \\
\hline $\begin{array}{l}\text { Cesarean section, no } \\
(\%)\end{array}$ & $38 / 55$ (69.1) & $57 / 90$ (63.3) & 0.479 & $\begin{array}{l}14 / 17 \\
(82.4)\end{array}$ & $\begin{array}{l}24 / 28 \\
(85.7)\end{array}$ & 1.000 \\
\hline $\begin{array}{l}\text { Initial } \mathrm{SpO}_{2} \text {, median } \\
\text { (IQR), \% }\end{array}$ & $92(87-97)$ & $91(85-96)$ & 0.270 & $\begin{array}{l}81(70- \\
93)\end{array}$ & $83(75-91)$ & 0.888 \\
\hline $\begin{array}{l}\text { Initial } \mathrm{FiO}_{2} \text {, median } \\
(\mathrm{IQR}), \%\end{array}$ & $25(23-30)$ & $25(21-30)$ & 0.525 & $\begin{array}{l}40(38- \\
40)\end{array}$ & $40(40-40)$ & 0.944 \\
\hline \multicolumn{7}{|l|}{ Initial Therapy } \\
\hline HHFNC, no (\%) & 4/55 (7.3) & $18 / 90(20.0)$ & & $\begin{array}{l}2 / 17 \\
(11.8)\end{array}$ & $3 / 28(10.7)$ & \\
\hline CPAP or NPPV, no (\%) & $51 / 55(92.7)$ & $72 / 90(80.0)$ & 0.038 & $\begin{array}{l}15 / 17 \\
(88.2)\end{array}$ & $\begin{array}{l}25 / 28 \\
(89.3)\end{array}$ & 1.000 \\
\hline $\begin{array}{l}\text { Air leakage during } \\
\text { hospitalization, no (\%) }\end{array}$ & 10/55 (18.2) & $12 / 90(13.3)$ & 0.430 & $\begin{array}{l}1 / 17 \\
(5.9)\end{array}$ & $\begin{array}{l}10 / 28 \\
(35.7)\end{array}$ & 0.033 \\
\hline $\begin{array}{l}\text { MV during } \\
\text { hospitalization, no (\%) }\end{array}$ & $7 / 55$ (12.7) & $11 / 90(12.2)$ & 0.929 & $\begin{array}{l}11 / 17 \\
(64.7)\end{array}$ & $\begin{array}{l}18 / 28 \\
(64.3)\end{array}$ & 0.977 \\
\hline $\begin{array}{l}\text { Respiratory support } \\
\text { days, median (IQR), } \\
\text { days }\end{array}$ & $3(2-4)$ & $3(2-4)$ & 0.563 & $\begin{array}{l}6(4- \\
7.5)\end{array}$ & $5(3-8.8)$ & 0.723 \\
\hline $\begin{array}{l}\text { Hospital stays, median } \\
\text { (IQR), days }\end{array}$ & $8(6-9)$ & $7(5-9)$ & 0.654 & $9(7-13)$ & $9.5(8-12)$ & 0.653 \\
\hline
\end{tabular}

Moderate-to-severe $\mathrm{RD}(n=45)$

$\mathrm{RD}$ : respiratory distress; NIV: non-invasive ventilation; $\mathrm{SpO}_{2}$ : saturation of partial pressure oxygen; $\mathrm{FiO}_{2}$ : fraction of inspired oxygen; HHFNC: humidified high flow nasal cannula; CPAP: continuous positive airway pressure; NPPV: non-invasive positive pressure ventilation; MV: mechanical ventilation

\section{Figures}


Late-preterm and term neonates $\geq 35$ weeks' gestation

Admitted between January 2016 and December 2020

$$
(N=1,709)
$$

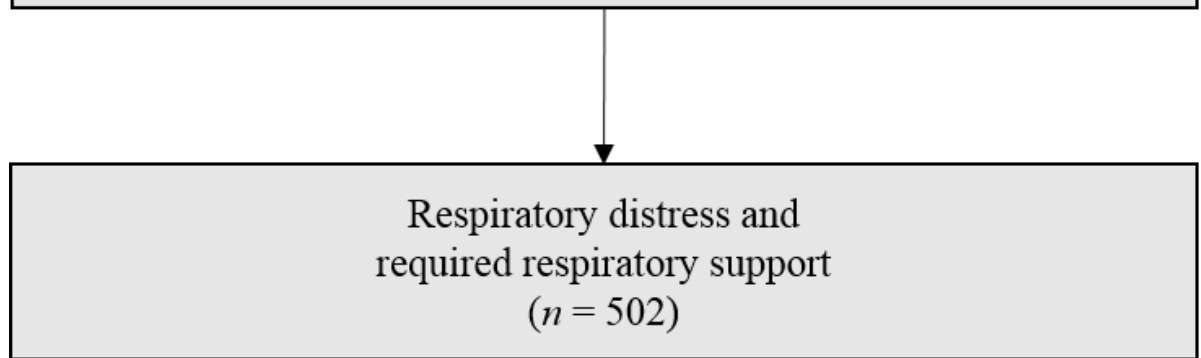

Excluded

- Infants with major congenital/chromosomal anomalies $(\mathrm{n}=58)$

- Infants with birth asphyxia $(\mathrm{n}=20)$

- Infants with meconium-stained amniotic fluids $(\mathrm{n}=53)$

- Infants who immediately received mechanical ventilation $(\mathrm{n}=21)$

- Infants with spontaneous pneumothorax $(\mathrm{n}=18)$

- Infants with pneumonia or sepsis $(\mathrm{n}=11)$

- Infants with idiopathic pulmonary hypertension of the newborn $(\mathrm{n}=4)$

- Infants with non-pulmonary problem $(\mathrm{n}=32)$

- Infants who received initial respiratory therapy at $\geq 24 \mathrm{~h}$ of age $(\mathrm{n}=8)$

Received non-invasive ventilation

as primary respiratory therapy at $<24 \mathrm{~h}$ of age $(n=277)$

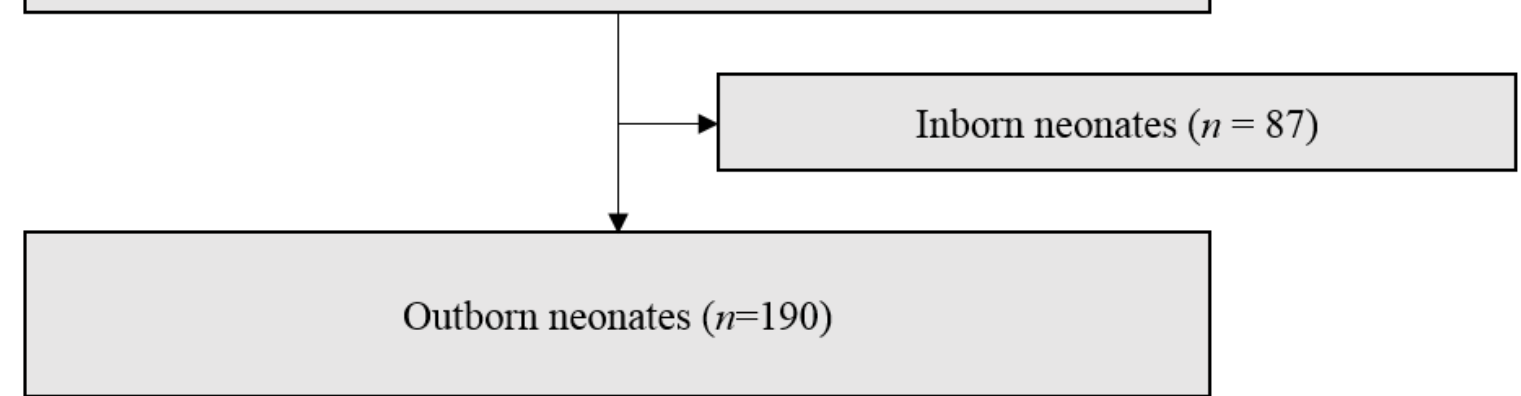

Figure 1

Flow chart of the study population 
$\square$ Mild RD - mechanical ventilation

$\square$ Mild RD - air leakeage

$\square$ Moderate-to-Severe RD - mechanical ventilation

- Moderate-to-Severe RD - air leakeage

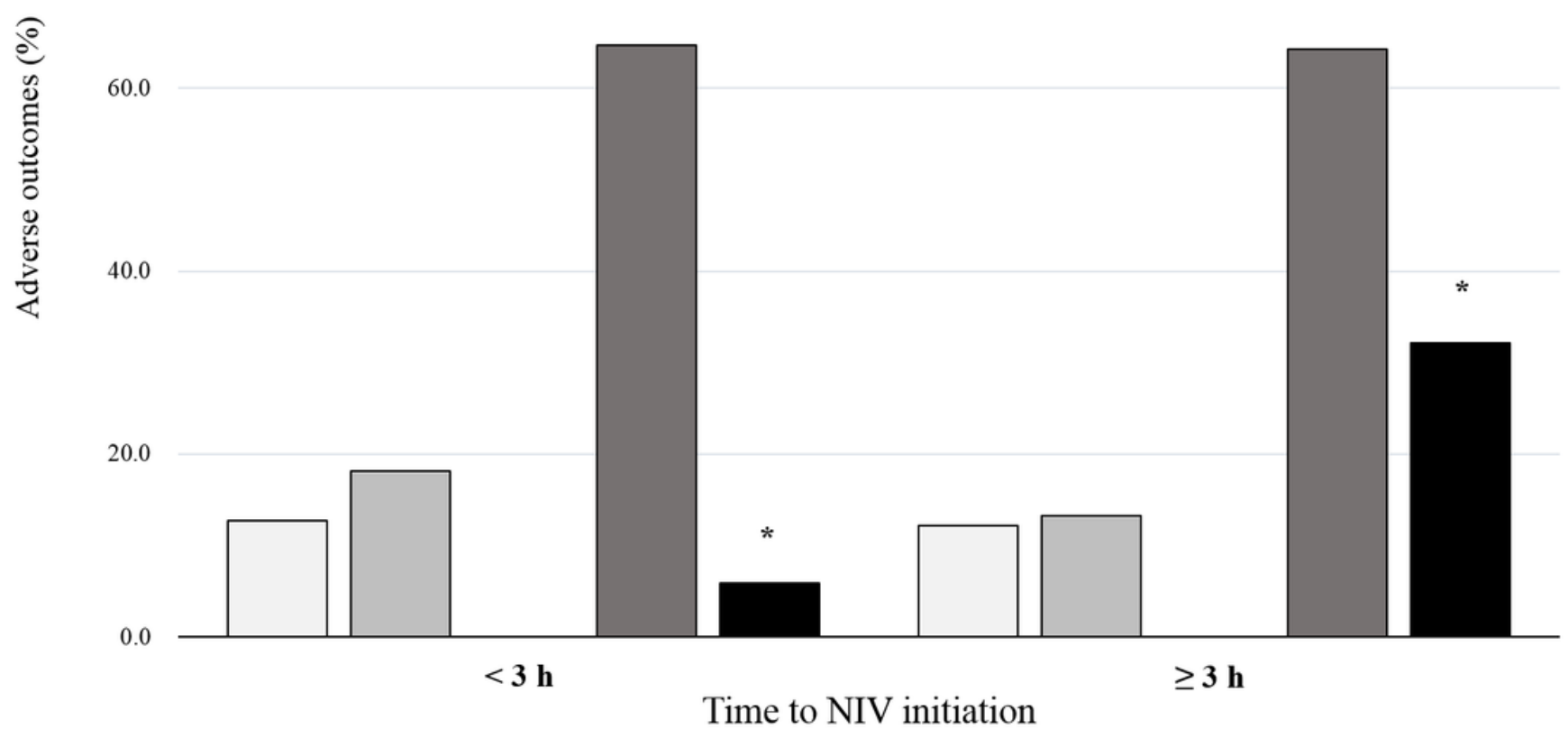

Figure 2

Adverse outcomes grouped according to the time of non-invasive ventilation initiation ( $3 \mathrm{~h}$ ) in mild or moderate-to-severe respiratory distress ${ }^{*} \mathrm{P}<0.05$. RD, respiratory distress; $\mathrm{NIV}$, non-invasive ventilation.

\section{Supplementary Files}

This is a list of supplementary files associated with this preprint. Click to download.

- supplementaltablesEurJpediatrics.pdf 